\title{
PECULIAR ASPECTS OF CRACKING IN PRESTRESSED REINFORCED CONCRETE T-BEAMS
}

\author{
VAsyl Karpiuk $^{a}$, Yulita Somina ${ }^{a, *}$, Fedir KArPiUK ${ }^{a}$, Irina KarPiUK ${ }^{b}$ \\ ${ }^{a}$ Odesa State Academy of Civil Engineering and Architecture, Faculty of Civil Engineering, Department of \\ Reinforced Concrete Structures and Transport Facilities, Didrihsona Street 4, 65029 Odesa, Ukraine \\ ${ }^{b}$ Odesa State Academy of Civil Engineering and Architecture, Faculty of Civil Engineering, Department of \\ Basements and Foundations, Didrihsona Street 4, 65029 Odesa, Ukraine \\ * corresponding author: syomina3091@ukr.net
}

ABSTRACT. In order to study the cracking of prestressed reinforced concrete T-shaped beam structures, the authors planned and carried out a full-scale experiment with five variable factors. The following factors were chosen as variable factors: the relative span of the shear, the ratio of the table overhang width to the thickness of the beam rib, the ratio of the table overhang thickness to the working height of the beam section, the coefficient of transverse reinforcement, the level of prestressing in the working reinforcement. The article describes the cracking process and the destruction of test beams. It was found that the loading level of an opening of inclined cracks is $53 \%$ larger than the loading level of a normal crack opening. Mathematical models of bending moments and transverse forces of cracking were built using the "COMPEX" software. Also, the mathematical models of the crack opening width and the projection length of a dangerous inclined crack were obtained. These models are based on the experimental data. Analysing the obtained models, the complex influence of variable factors on the main parameters of crack formation and crack resistance was established. In particular, it was found that the prestress level in the working reinforcement has the greatest effect on the bending moment of cracking. In this case, the value of the shear force of cracking significantly depends on both the prestressing level in the reinforcement and the relative span of the shear. On the basis of the experimental data, the empirical expression is obtained for determining the projection of a dangerous inclined crack for prestressed reinforced concrete T-shaped beams. The resulting equation can be used to calculate a shear reinforcement.

KEYWORDS: Reinforced concrete, prestressing, T-beam, inclined section, normal crack, diagonal crack, cracking, transverse force, bending moment.

\section{INTRODUCTION}

Solving the problems of capital construction is associated with the technical progress in the field of concrete and reinforced concrete, as they are the most common materials for supporting structures in modern construction. Reinforced concrete elements with various cross-sectional shapes (rectangular, T-shaped, I-shaped, trapezoidal, etc.) are a significant part of prefabricated, monolithic and precast-monolithic structures, however, the data about the work under the load are rather limited. The data of some researches in this area are presented in works [1] 3 .

Despite its widespread use, one of the disadvantages of reinforced concrete is the early formation of cracks in the tensioned zone, and as a result, the rapid growth of structural deflections to the ultimate value. The problem of crack opening has a considerable importance for ensuring the joint deformation of the reinforcement and the concrete, which determines the durability, rigidity and ensures the full use of the bearing capacity of reinforced concrete structures. Each crack appearance in a reinforced concrete unit indicates that there has been a discharge of accumulated stresses in this area of the structure. The cause of cracks is internal tensile stresses, which can arise due to the internal processes in the unit (concrete shrinkage, loss (outflow) of hydration heat; reinforcement corrosion, etc.) and the external loads on the structure (temperature, force, shock actions, etc.). The development of a calculating apparatus for crack formation in reinforced concrete structures is very difficult because the main hypothesis of the mechanics of a solid deformable body (the hypothesis of continuity) 4, 5] is not applicable here, the continuity is violated by the presence of macro-cracks. The use of simplified approaches is also impossible, since the permissible error in this case exceeds the characteristic of the crack opening width, measured during the experiments using a microscope.

In order to increase the rigidity and crack resistance, prestressing is widely used in reinforced concrete structures; it is used in beams, slabs, and trusses. In addition, it reduces the weight of the structure and, as a result, it increases the efficiency and the possibility of a rational use of high-strength reinforcement. There are 


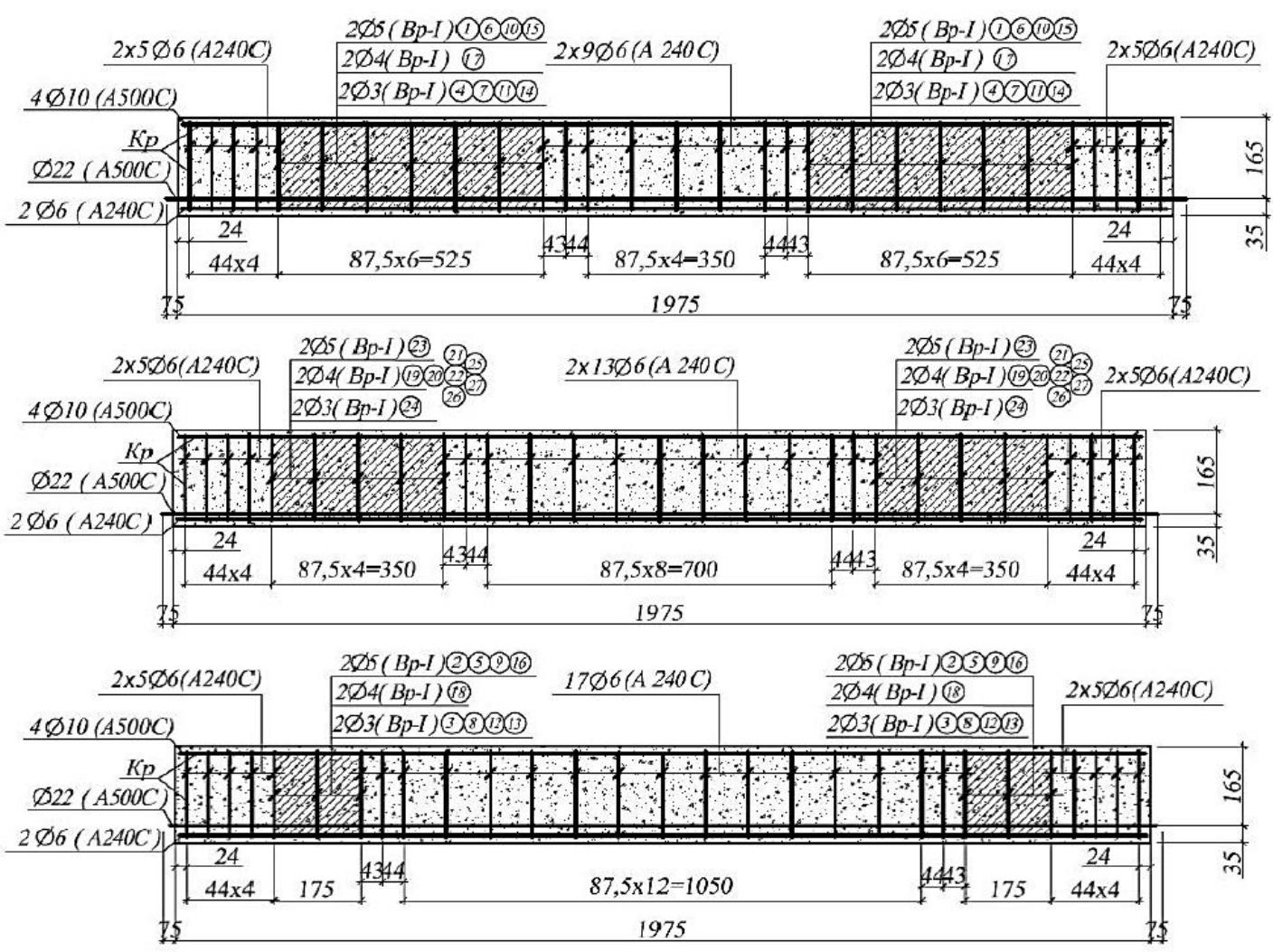

FiguRE 1. Dimensions and reinforcement of the tested beams with large, medium and small shear span.

also some disadvantages: increased labour intensity and the necessity for a special equipment, lower fire resistance; reinforcing prestressed structures is more complicated than conventional ones; a high-strength reinforcement loses its plastic properties faster with corrosion and there is a danger of brittle fracture of structures. Following this line of reasoning, it is necessary to determine the appropriateness of applying prestressing in individual cases. An investigation on the crack pattern at a failure and evolution of a compressive strut inclination and crack inclination at a failure from both the theoretical and the experimental point of view was reported in [6] 8 .

Based on the foregoing, the accumulation of experimental data, as well as the identification of new patterns of this issue are urgent and practically useful scientific task.

\section{MATERIALS AND METHOdS}

In order to study this theme, T-shaped beams were manufactured and tested 9. The width of the tables was taken as a multiple of the rib width: $2 \mathrm{~b}, 3 \mathrm{~b}, 4 \mathrm{~b}$. Their heights were 30,45 and $60 \mathrm{~mm}$. The calculated span length was $1975 \mathrm{~mm}$. As a prestressed working reinforcement in the form of a separate rod, we used thermomechanically hardened reinforcement of a deformed (feather) profile, class A500C $\varnothing 22 \mathrm{~mm}$ [10, 11]. In addition to the specified rod, the beams were reinforced with two vertical flat frames, an upper mesh and separate rods. Dimensions of the tested beams and their reinforcement is shown in Fig. 1.

The following factors were selected as variable factors: $X_{1}$ is the relative span of the shear $\left(a / h_{0}\right) ; X_{2}$ is the ratio of the width of the table overhangs to the rib thickness $\left(b_{f}^{/} / b\right) ; X_{3}$ is the ratio of the thickness of the table overhangs to the working height of the section $\left(h_{f}^{/} / h_{0}\right) ; X_{4}$ is the coefficient of the transverse reinforcement $\left(\rho_{s w}\right) ; X_{5}$ is the prestressing level in the working reinforcement $\left(P / f_{c d} b h_{0}\right)$.

In accordance with the accepted test procedure [9], the prototype beams were tested according to the scheme of a single-span free-support beam on 2 seats at the age of $100 \ldots 120$ days (Fig. 2). 27 test beams were tested.

\section{Results}

During the testing, the prototypes deformed with the marked deflections on a load increment) [12. At the same time, during the process of loading, the normal cracks appeared in the simple bending zone, and then there were inclined ones in the support areas (Fig. 3, 4, 4 . 


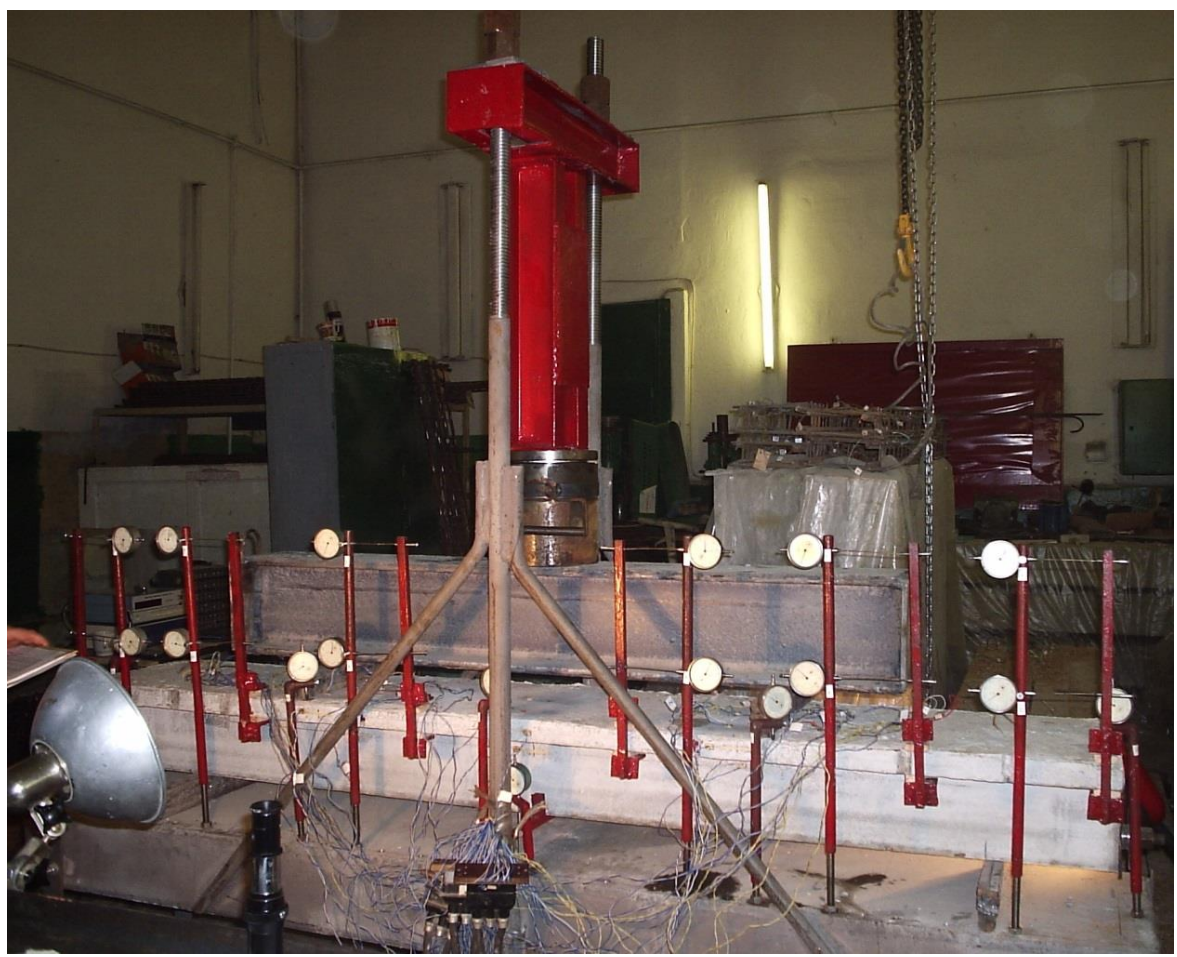

Figure 2. Prototype beam during the tests.

The absolute majority (more than $90 \%$ ) of the prototype beams fractured in the support areas, and the rest of them did along both the normal and the inclined sections [13, 14. During the loading, the first normal cracks formed in the bottom of the beam rib in the simple bending zone, and then in the shear span. With the load increasing, they developed as follows: in the simple bending zone - without changing the original direction, and in the shear span - deviating towards the application of a concentrated force and gradually turning into inclined cracks (the first type of inclined cracks). In addition to normal cracks developing into inclined ones, particular inclined cracks also formed in the middle height of the section of the beam rib (second type) over existing normal cracks and in the zone where they are absent.

With a further increase of the load, inclined cracks developed towards the compressed and stretched sides of the beam, and one of them is the critical one - it opened up most intensively.

In the experiments, there were three destruction forms of the support areas of the beams [15: along a dangerous inclined crack from the dominated effect of the shearing force (A pattern, Fig. 3, 4); along a dangerous inclined crack from the dominated effect of the bending moment (B pattern, Fig. 3, 4); or along a compressed inclined band (C pattern, Fig. 3, 4).

With the destruction of the beams in the form $\mathrm{A}$ and $\mathrm{B}$, a dangerous inclined crack, having reached a compressed table, penetrated it or developed along its lower side, and then penetrated the table.

Subsequently, a beam destruction from crushing or concrete shearing in the compressed zone occurred with the possible achievement of the yield point in the prestressed reinforcement at the mouth of the inclined crack. With a relatively small shear span, the beam destruction occurred from a concrete crushing along an inclined compressed band between inclined cracks in the rib in the direction from the load to the support.

Experimental data on bending moments and shearing forces of cracking are presented in Table 1 .

The investigated limit here is the moment and the shearing force of the beginning of the cracks. It is generally accepted that the first cracks in reinforced concrete beams appear at the level 20-30\% of the total breaking load, and in prestressed ones - at the level of $30 \%$. Analysing the table, this hypothesis cannot be observed in all the experiments. For example, in the experiments with more powerful reinforcement, the cracking rate is more than $30 \%$, and in the experiments with less powerful reinforcement, the cracking rate is about $10 \%$. These results must be taken into account in the design process.

The interpretation of the experimental data was carried out by analysing the experimental statistical dependencies (mathematical models). These models were obtained using the "COMPEX" software, which was developed at the Odessa State Academy of Civil Engineering and Architecture under the guidance of Professor V. A. Voznesenskiy in 1991 on the basis of works [16, 17. Analysing these models, it is possible to determine the influence of design factors on the output parameter, both individually and interacting with each other. The theoretical pre-condition of PC is based on the theory of experiment planning, the theory of mathematical 

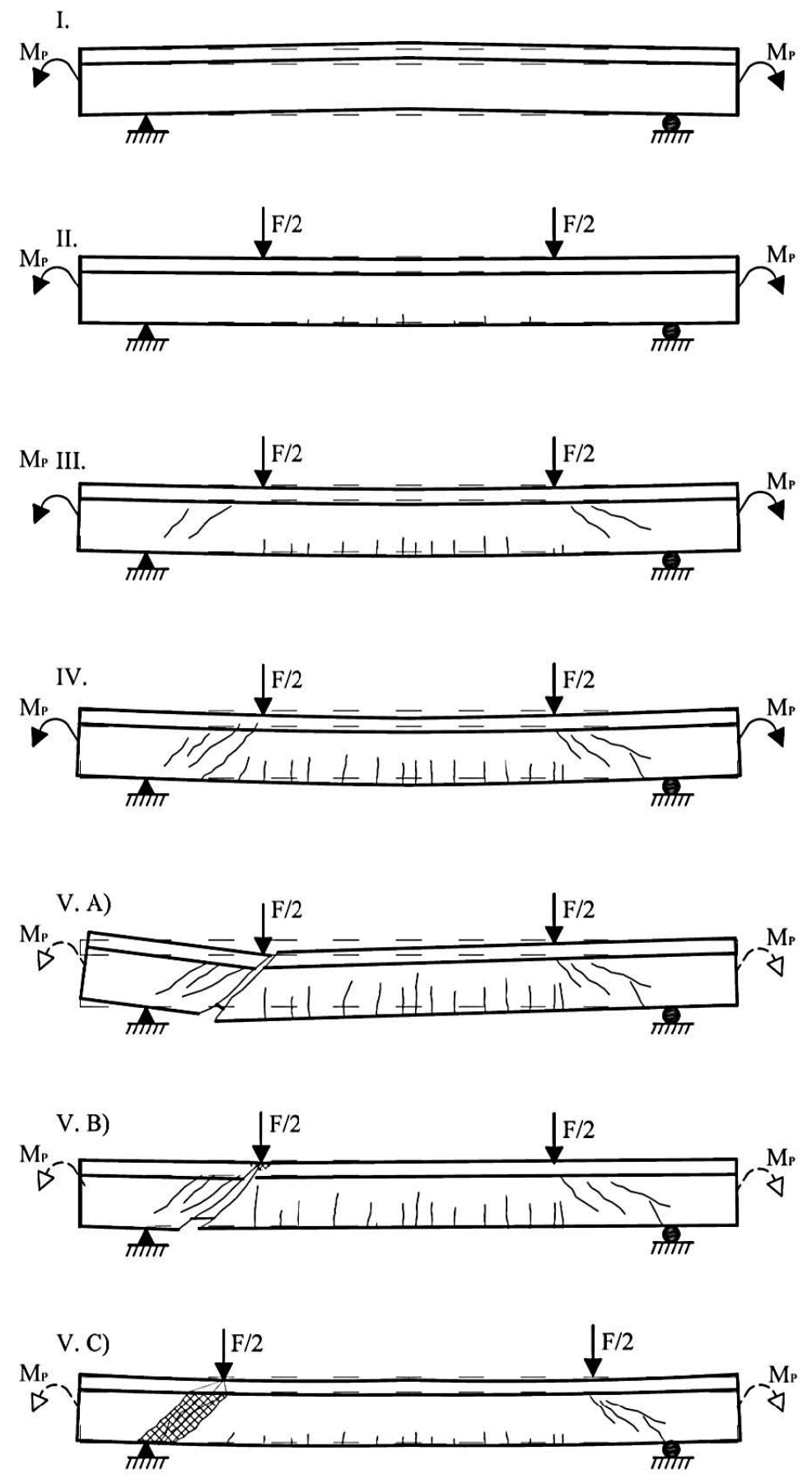

I - transfer of prestressing in reinforcement to concrete; II - formation of normal cracks in the zone of pure bending; III - growth of normal cracks and the formation of inclined cracks in shear spans; IV - development of normal and inclined cracks with an intersection of compressed beam flange and formation of new inclined cracks; V.A) - the beam destruction with the displacement of area near the support and with the reinforcement kink; V.B) - the beam destruction due to the prevailing action of the bending moment; V.C) - the beam destruction due to the crushing of the beam rib concrete

FiguRE 3. Development of normal and inclined cracks and destruction patterns of test beams. 


\begin{tabular}{|c|c|c|c|c|c|c|c|c|}
\hline No. & $\begin{array}{c}X_{1} \\
a / h_{0} \\
\end{array}$ & $\begin{array}{c}X_{2} \\
b_{f}^{/} / b\end{array}$ & $\begin{array}{c}X_{3} \\
b_{f}^{/} / h_{0} \\
\end{array}$ & $\begin{array}{l}X_{4} \\
\rho_{s w}\end{array}$ & $\begin{array}{c}X_{5} \\
P / f_{c d} b h_{0}\end{array}$ & $\begin{array}{l}M_{c r c, \perp}(\mathrm{kNm}) \\
M_{c r c, /}(\mathrm{kNm})\end{array}$ & $\begin{array}{l}F_{c r c, \perp}^{a c c .}(\mathrm{kN}) \\
F_{c r c, /}^{a c c .}(\mathrm{kN})\end{array}$ & $F_{u}(\mathrm{kN})$ \\
\hline 1 & 3.18 & 4.0 & 0.36 & 0.0056 & 0.584 & $\begin{array}{l}13.37 \\
16.49\end{array}$ & $\begin{array}{l}25.5 \\
31.4\end{array}$ & 85.50 \\
\hline 2 & 1.06 & 2.0 & 0.36 & 0.0056 & 0.584 & $\begin{array}{c}11.90 \\
7.63\end{array}$ & $\begin{array}{l}68.0 \\
43.6\end{array}$ & 93.00 \\
\hline 3 & 1.06 & 4.0 & 0.18 & 0.0020 & 0.0 & $\begin{array}{l}2.84 \\
4.94\end{array}$ & $\begin{array}{c}16.20 \\
28.2\end{array}$ & 76.00 \\
\hline 4 & 3.18 & 2.0 & 0.18 & 0.0020 & 0.0 & $\begin{array}{c}1.99 \\
13.65 \\
\end{array}$ & $\begin{array}{l}3.80 \\
26.0\end{array}$ & 64.00 \\
\hline 5 & 1.06 & 4.0 & 0.18 & 0.0056 & 0.584 & $\begin{array}{c}12.67 \\
5.74\end{array}$ & $\begin{array}{l}72.4 \\
38.2\end{array}$ & 93.20 \\
\hline 6 & 3.18 & 2.0 & 0.18 & 0.0056 & 0.584 & $\begin{array}{l}11.83 \\
13.34\end{array}$ & $\begin{array}{l}22.5 \\
25.4\end{array}$ & 80.30 \\
\hline 7 & 3.18 & 4.0 & 0.36 & 0.0020 & 0.0 & $\begin{array}{c}3.54 \\
15.08\end{array}$ & $\begin{array}{l}6.70 \\
28.7\end{array}$ & 69.30 \\
\hline 8 & 1.06 & 2.0 & 0.36 & 0.0020 & 0.0 & $\begin{array}{l}2.07 \\
6.42\end{array}$ & $\begin{array}{l}11.8 \\
37.6\end{array}$ & 76.80 \\
\hline 9 & 1.06 & 4.0 & 0.36 & 0.0056 & 0.0 & $\begin{array}{l}3.57 \\
7.77\end{array}$ & $\begin{array}{l}20.4 \\
44.4\end{array}$ & 95.00 \\
\hline 10 & 3.18 & 2.0 & 0.36 & 0.0056 & 0.0 & $\begin{array}{c}2.03 \\
11.13\end{array}$ & $\begin{array}{l}3.90 \\
21.2\end{array}$ & 81.00 \\
\hline 11 & 3.18 & 4.0 & 0.18 & 0.0020 & 0.584 & $\begin{array}{l}12.63 \\
11.87\end{array}$ & $\begin{array}{l}24.1 \\
22.6\end{array}$ & 64.00 \\
\hline 12 & 1.06 & 4.0 & 0.18 & 0.0020 & 0.584 & $\begin{array}{c}11.87 \\
7.14\end{array}$ & $\begin{array}{l}67.8 \\
40.8\end{array}$ & 78.30 \\
\hline 13 & 1.06 & 4.0 & 0.36 & 0.0020 & 0.584 & $\begin{array}{c}13.47 \\
8.82\end{array}$ & $\begin{array}{l}76.6 \\
50.4\end{array}$ & 64.80 \\
\hline 14 & 3.18 & 2.0 & 0.36 & 0.0020 & 0.584 & $\begin{array}{l}11.86 \\
12.92\end{array}$ & $\begin{array}{l}22.6 \\
24.6\end{array}$ & 88.80 \\
\hline 15 & 3.18 & 4.0 & 0.18 & 0.0056 & 0.0 & $\begin{array}{c}2.80 \\
12.08\end{array}$ & $\begin{array}{c}5.3 \\
23.0\end{array}$ & 89.80 \\
\hline 16 & 1.06 & 2.0 & 0.18 & 0.0056 & 0.0 & $\begin{array}{l}2.03 \\
5.53\end{array}$ & $\begin{array}{l}11.6 \\
31.6\end{array}$ & 80.00 \\
\hline 17 & 3.18 & 3.0 & 0.27 & 0.0036 & 0.292 & $\begin{array}{c}7.51 \\
14.65\end{array}$ & $\begin{array}{l}14.3 \\
27.9\end{array}$ & 83.00 \\
\hline 18 & 1.06 & 3.0 & 0.27 & 0.0036 & 0.292 & $\begin{array}{l}7.54 \\
7.54\end{array}$ & $\begin{array}{l}43.1 \\
43.1\end{array}$ & 81.00 \\
\hline 19 & 2.12 & 4.0 & 0.27 & 0.0036 & 0.292 & $\begin{array}{c}8.10 \\
11.66\end{array}$ & $\begin{array}{l}23.1 \\
33.3\end{array}$ & 81.00 \\
\hline 20 & 2.12 & 2.0 & 0.27 & 0.0036 & 0.292 & $\begin{array}{c}6.95 \\
10.99\end{array}$ & $\begin{array}{l}19.9 \\
31.4\end{array}$ & 82.00 \\
\hline 21 & 2.12 & 3.0 & 0.36 & 0.0036 & 0.292 & $\begin{array}{c}7.72 \\
12.29\end{array}$ & $\begin{array}{l}22.1 \\
35.1\end{array}$ & 80.00 \\
\hline 22 & 2.12 & 3.0 & 0.18 & 0.0036 & 0.292 & $\begin{array}{c}7.33 \\
10.32\end{array}$ & $\begin{array}{l}20.9 \\
29.5\end{array}$ & 90.00 \\
\hline 23 & 2.12 & 3.0 & 0.27 & 0.0056 & 0.292 & $\begin{array}{c}7.52 \\
11.55\end{array}$ & $\begin{array}{l}21.5 \\
33.0\end{array}$ & 70.00 \\
\hline 24 & 2.12 & 3.0 & 0.27 & 0.0020 & 0.292 & $\begin{array}{c}7.52 \\
11.55\end{array}$ & $\begin{array}{l}21.5 \\
33.0\end{array}$ & 82.00 \\
\hline 25 & 2.12 & 3.0 & 0.27 & 0.0020 & 0.584 & $\begin{array}{l}13.00 \\
12.11\end{array}$ & $\begin{array}{l}37.1 \\
34.6\end{array}$ & 80.00 \\
\hline 26 & 2.12 & 3.0 & 0.27 & 0.0020 & 0.0 & $\begin{array}{c}2.45 \\
10.47\end{array}$ & $\begin{array}{c}7.0 \\
29.9\end{array}$ & 81.00 \\
\hline 27 & 2.12 & 3.0 & 0.27 & 0.0020 & 0.292 & $\begin{array}{c}7.53 \\
10.85\end{array}$ & $\begin{array}{l}21.5 \\
31.0\end{array}$ & 78.30 \\
\hline
\end{tabular}

TABLE 1. Experimental data of bending moments and transverse forces. 


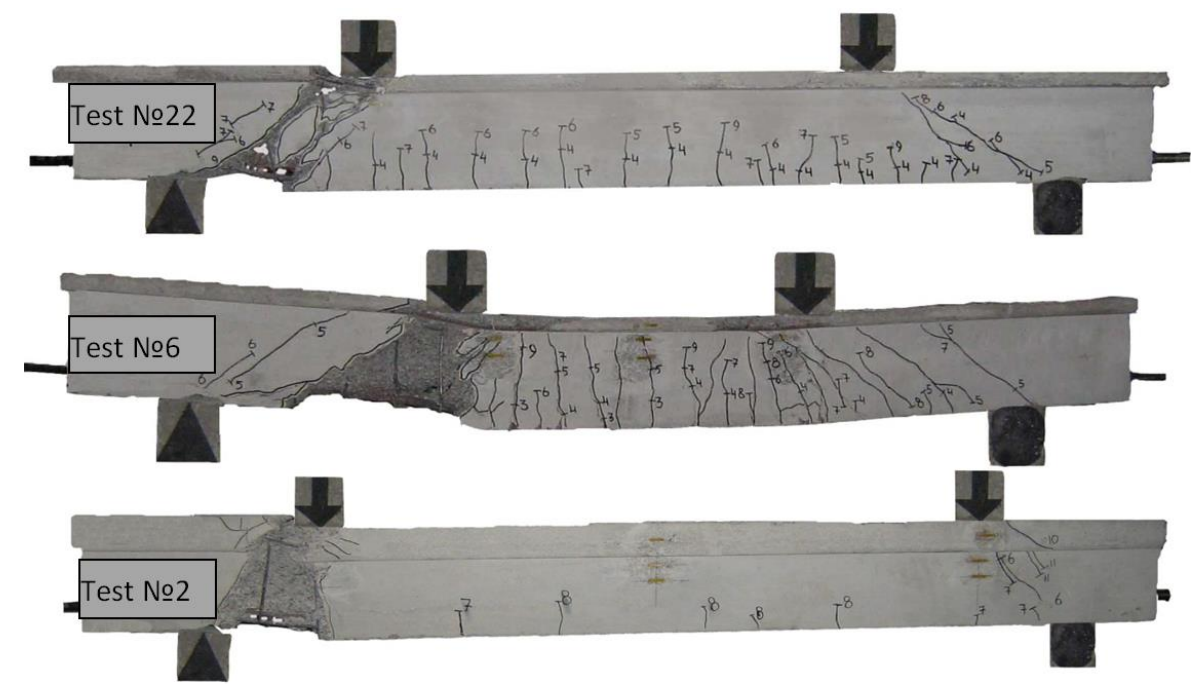

test No. 22 - destruction pattern A; test No. 6 - destruction pattern B; test No. 2 - destruction pattern C

Figure 4. Photos of the test specimens with different destruction patterns.

modelling, and also on the methods of statistics. In order to determine the influence coefficients of the examined factors, it was necessary to assign the program matrix of the test plan, which reflected variation levels of these factors as well as the experimental values of the output parameter. The specified PC is used under the assumption of the distribution of the investigated random value according to the normal Gaussian law and, as a consequence, the application of the least squares method.

Thus, the experimental-statistical dependences for the bending moment, causing normal cracking in simple bending zone and the corresponding transverse load, have been obtained:

$$
\hat{Y}\left(M_{c r c, \perp}\right)=7.55+0.58 X_{2}+0.19 X_{3}+5.0 X_{5}+0.12 X_{5}^{2}+0.17 X_{2} X_{3} \quad(\mathrm{kNm})
$$

$$
\begin{array}{r}
\hat{Y}\left(F_{c r c, \perp}^{a c c .}\right)=21.6-14.4 X_{1}+2.1 X_{2}+0.7 X_{3}+18.3 X_{5}+7.1 X_{1}^{2}-0.4 X_{5}^{2}-1.1 X_{1} X_{2}- \\
-0.4 X_{1} X_{3}-9.4 X_{1} X_{5}+0.7 X_{2} X_{3}
\end{array}
$$

The value of the coefficients at factors $X_{i}$ corresponds to the degree of their influence on the formation moment of normal cracks in relation to the absolute term $b_{0}$. The "+" sign indicates that increasing this factor within the range of variation, the torque value will increase.

So, three factors affect the time of cracking normal to the longitudinal axis of the beam (Eq. 1): the ratio of the table overhangs width to the rib thickness $b_{f}^{/} / b\left(X_{2}\right)$, the ratio of the table overhangs thickness to the working height of the section $h_{f}^{\prime} / h_{0}\left(X_{3}\right)$ and the stress level in the working reinforcement $\sigma_{s p}\left(X_{5}\right)$. Analysis of Eq. 1 shows that the factor $X_{5}$ has the greatest influence on the moment $\mathrm{M}_{c r c, \perp}$. So, increasing prestress $\sigma_{s p}$ from 0 to $30 \mathrm{kN} / \mathrm{cm}^{2}$, the cracking moment in a stretched rib increases relative to the average value $\left(b_{0}\right.$ is the average value of the output parameter from the entire series of the experiments, determined with the theory of mathematical planning according to the standard procedure) by $135 \%$.

Increasing factors $X_{2}$ and $X_{3}$, it increases by $16 \%$ and $8.5 \%$, respectively. The presence of a positive sign in the case of the quadratic effect $X_{5}^{2}$ indicates that with a further increase of the prestress level outside the range of this factor variation, there will be a significant increase of the crack formation moment. The output parameter increases with a simultaneous increasing of factors $X_{2}$ and $X_{3}$ (interaction). Factor $X_{4}$ is insignificant, its influence was less than $5 \%$ in relation to the absolute term of the model. Consequently, this factor is not reflected in the model.

From Eq. 2, we can see that the load corresponding to the formation of normal cracks is significantly influenced by both the prestressing level and the relative shearing span. Increasing $X_{1}$ from 1.06 to 3.18 decreases the value $F_{c r c, \perp}^{a c c}$, , in relation to the average value, by $131 \%$, and increasing $X_{5}$ increases it by $175 \%$. There is also the interaction of the factors with each other. When simultaneously increasing $a / h_{0}$ and $\sigma_{s p}$, $a / h_{0}$ and $b_{f}^{\prime} / b, a / h_{0}$ and $h_{f}^{\prime} / h_{0}$ also increase simultaneously and the value of $F_{c r c, \perp}^{a c c}$ decreases. Factor $X_{4}$ was insignificant, its influence was less than $5 \%$ in relation to the absolute term of the model. Consequently, this factor is not reflected in the model. 
In [18 20, one can find the information on the crack resistance of normal sections of the investigated elements, but, as a rule, there is no comprehensive approach to assess the influence of experimental factors on the considered output parameter (crack resistance). The researchers in 21 choose one or two factors for the analysis and study their influence. But with such an approach to the study of this phenomenon, it is impossible to set the interaction of the factors with each other, while it naturally often exists.

Before the normal cracks were evident, the investigated reinforced concrete element deformed like an elastic body: the increase in deformations and deflections of the element was proportional to the increase in the external load.

Before the first cracks were evident, the stresses in the tensioned concrete decreased to zero, and in tensioned reinforcement, they increased abruptly.

By processing the experimental data on the inclined crack formation in the shearing span, adequate mathematical models were obtained for the shearing force and the corresponding bending moment at this loading level:

$$
\begin{aligned}
\hat{Y}\left(F_{c r c, /}=Q_{c r c, /}\right)=33.0-7.0 X_{1}+1.0 X_{2}+2.8 X_{3}+2.3 X_{5}+2.3 X_{1}^{2}-0.9 X_{2}^{2} \\
-1.0 X_{3}^{2}-1.0 X_{5}^{2}-1.8 X_{1} X_{3}-1.6 X_{1} X_{5}+2.4 X_{2} X_{3}+1.0 X_{2} X_{4}
\end{aligned}
$$

$$
\begin{aligned}
\hat{Y}\left(M_{c r c, /}^{a c c .}\right)=11.51+ & 3.23 X_{1}+0.33 X_{2}+0.70 X_{3}+0.57 X_{5}-0.52 X_{1}^{2}-0.29 X_{2}^{2} \\
& -0.30 X_{3}^{2}-0.32 X_{5}^{2}+0.17 X_{1} X_{2}+0.84 X_{2} X_{3}+0.34 X_{2} X_{4}+0.18 X_{3} X_{5} \quad(\mathrm{kNm})
\end{aligned}
$$

The value of the shearing force, at which inclined cracks appear, is influenced by four factors: the relative shearing span, the ratio of the width of the table overhangs to the thickness of the rib, the ratio of the thickness of the table overhangs to the working height of the section, and the prestressing level in the working reinforcement. An analysis of the Eq. 3 shows that factor $X_{1}$ has the greatest influence on the shearing force. So, increasing the relative shear span from 1.06 to 3.08 , the shearing force of the crack formation will decrease with respect to the average value $\left(b_{0}\right)$ by $42 \%$. Increasing the ratio of the width of the table overhangs to the thickness of the rib from 2 to 4 will increase the indicated force by $6 \%$. Factors $X_{3}$ and $X_{5}$ have a more significant influence than factor $X_{2}$. Accordingly, increasing $h_{f}^{/} / h_{0}$ from 0.18 to 0.36 will increase the shearing force of the crack formation of inclined cracks by $17 \%$, and $\sigma_{s p}$ from 0 to $30 \mathrm{kN} / \mathrm{cm}^{2}-$ by $14 \%$.

The presence of a negative sign in the case of quadratic effects $X_{2}^{2}, X_{3}^{2}$ and $X_{5}^{2}$ indicates that with a further increase of these factors outside of their variation, there will be no significant increasing of the shearing force, at which the inclined cracks appear.

There is also the mutual interaction of the factors. If $a / h_{0}$ and $\sigma_{s p}$ increase simultaneously, the value $F_{c r c}$, will decrease. If $b_{f}^{/} / b$ and $h_{f}^{/} / h_{0}, h_{f}^{/} / h_{0}$ and $\rho_{s w}$ increase simultaneously, the value $F_{c r c, /}$ will increase.

Comparing the experimental data with the calculated ones, it was found that the experimental values of the cracking load, as a rule, are higher than the calculated ones, which should be taken into account in the design process.

The obtained results on the opening width of normal cracks correspond to the experimental and calculated results 22 24.

When processing the experimental data, adequate experimental-statistical models (mathematical) were obtained that characterize the opening width of cracks normal and inclined to the longitudinal axis of the beam before its destruction under an external load $0,95 F_{u}$ :

$$
\begin{gathered}
\hat{Y}\left(w_{c r c \perp}^{0.95 F_{u}}\right)=0.157+0.011 X_{2}+0.011 X_{3}-0.032 X_{5}-0.002 X_{5}^{2}+0.009 X_{2} X_{3} \quad(\mathrm{~mm}) \\
\hat{Y}\left(w_{c r c /}^{0.95 F_{u}}\right)=0.765+0.101 X_{1}-0.079 X_{2}-0.012 X_{3}-0.019 X_{4}-0.042 X_{5}-0.072 X_{1} X_{2}-0.022 X_{1} X_{3} \\
-0.067 X_{1} X_{5}+0.006 X_{2} X_{3}+0.058 X_{2} X_{4}+0.026 X_{2} X_{5}+0.021 X_{3} X_{4}+0.006 X_{4} X_{5} \quad(\mathrm{~mm})
\end{gathered}
$$

As you can see in the model (5), the prestress level in the working reinforcement $\sigma_{s p}\left(X_{5}\right)$, the width ratio of the table overhangs to the thickness of the rib $b_{f}^{/} / b\left(X_{2}\right)$ and the thickness ratio of the table overhangs to the working height of the section $h_{f}^{/} / h_{0}\left(X_{3}\right)$ influence the opening width of normal cracks the most. 


\begin{tabular}{|c|c|c|c|c|c|c|c|c|}
\hline No. & $\begin{array}{c}X_{1}, \\
a / h_{0}\end{array}$ & $\begin{array}{c}X_{2}, \\
b_{f}^{\prime} / b\end{array}$ & $\begin{array}{c}X_{3}, \\
h_{f}^{\prime} / h_{0} \\
\end{array}$ & $\begin{array}{l}X_{4}, \\
\rho_{s w} \\
\end{array}$ & $\begin{array}{c}X_{5}, \\
P / f_{c d} b h_{0}\end{array}$ & $w_{c r c, \perp}^{0.95 F_{u}}(\mathrm{~mm})$ & $w_{c r c, /}^{0.95 F_{u}}(\mathrm{~mm})$ & $c_{0}(\mathrm{~cm})$ \\
\hline 1 & 3.18 & 4.0 & 0.36 & 0.0056 & 0.584 & 0.16 & 0.66 & 38 \\
\hline 2 & 1.06 & 2.0 & 0.36 & 0.0056 & 0.584 & 0.12 & 0.63 & 13 \\
\hline 3 & 1.06 & 4.0 & 0.18 & 0.0020 & 0.0 & 0.18 & 0.57 & 16 \\
\hline 4 & 3.18 & 2.0 & 0.18 & 0.0020 & 0.0 & 0.18 & 1.30 & 46 \\
\hline 5 & 1.06 & 4.0 & 0.18 & 0.0056 & 0.584 & 0.12 & 0.70 & 13 \\
\hline 6 & 3.18 & 2.0 & 0.18 & 0.0056 & 0.584 & 0.11 & 0.84 & 38 \\
\hline 7 & 3.18 & 4.0 & 0.36 & 0.0020 & 0.0 & 0.22 & 0.70 & 46 \\
\hline 8 & 1.06 & 2.0 & 0.36 & 0.0020 & 0.0 & 0.18 & 0.75 & 15 \\
\hline 9 & 1.06 & 4.0 & 0.36 & 0.0056 & 0.0 & 0.22 & 0.68 & 15 \\
\hline 10 & 3.18 & 2.0 & 0.36 & 0.0056 & 0.0 & 0.18 & 1.04 & 46 \\
\hline 11 & 3.18 & 4.0 & 0.18 & 0.0020 & 0.584 & 0.12 & 0.64 & 38 \\
\hline 12 & 1.06 & 4.0 & 0.18 & 0.0020 & 0.584 & 0.11 & 0.75 & 13 \\
\hline 13 & 1.06 & 4.0 & 0.36 & 0.0020 & 0.584 & 0.16 & 0.67 & 13 \\
\hline 14 & 3.18 & 2.0 & 0.36 & 0.0020 & 0.584 & 0.12 & 0.88 & 38 \\
\hline 15 & 3.18 & 4.0 & 0.18 & 0.0056 & 0.0 & 0.18 & 0.85 & 46 \\
\hline 16 & 1.06 & 2.0 & 0.18 & 0.0056 & 0.0 & 0.18 & 0.55 & 15 \\
\hline 17 & 3.18 & 3.0 & 0.27 & 0.0036 & 0.292 & 0.16 & 0.86 & 42 \\
\hline 18 & 1.06 & 3.0 & 0.27 & 0.0036 & 0.292 & 0.16 & 0.66 & 14 \\
\hline 19 & 2.12 & 4.0 & 0.27 & 0.0036 & 0.292 & 0.17 & 0.68 & 28 \\
\hline 20 & 2.12 & 2.0 & 0.27 & 0.0036 & 0.292 & 0.15 & 0.84 & 28 \\
\hline 21 & 2.12 & 3.0 & 0.36 & 0.0036 & 0.292 & 0.17 & 0.75 & 28 \\
\hline 22 & 2.12 & 3.0 & 0.18 & 0.0036 & 0.292 & 0.15 & 0.78 & 28 \\
\hline 23 & 2.12 & 3.0 & 0.27 & 0.0056 & 0.292 & 0.16 & 0.74 & 28 \\
\hline 24 & 2.12 & 3.0 & 0.27 & 0.0020 & 0.292 & 0.16 & 0.78 & 28 \\
\hline 25 & 2.12 & 3.0 & 0.27 & 0.0020 & 0.584 & 0.12 & 0.72 & 25 \\
\hline 26 & 2.12 & 3.0 & 0.27 & 0.0020 & 0.0 & 0.19 & 0.81 & 31 \\
\hline 27 & 2.12 & 3.0 & 0.27 & 0.0020 & 0.292 & 0.15 & 0.83 & 28 \\
\hline
\end{tabular}

TABle 2. Experimental data of normal and inclined cracks' width and data of a projection value of a dangerous inclined crack.

So, by increasing the prestressing level $\sigma_{s p}$ from 0 to $30 \mathrm{kN} / \mathrm{cm}^{2}$, the opening width of normal and inclined cracks will decrease, relative to the average value $\left(b_{0}\right)$, by 41 and $12 \%$, respectively. By increasing the width ratio of the table overhangs to the thickness of the rib $b_{f}^{/} / b$ from 2 to 4 and increasing the thickness ratio of the table overhangs to the working height $h_{f}^{\prime} / h_{0}$ from 0.18 to 0.36 , the opening width of normal cracks will increase by $14 \%$, and the opening width of inclined cracks will decrease by 21 and $23 \mid, \%$.

The presence of a negative sign in the case of the $X_{5}^{2}$ quadratic effect indicates that with a further increase of this factor level outside of its variation, there will be a more significant decrease in the opening width of cracks normal to the longitudinal axis of the beam.

The analysis of the mathematical model (6) shows that the relative shear span $a / h_{0}\left(X_{1}\right)$, the width ratio of the table overhangs to the rib thickness $b_{f}^{/} / b$ and the prestressing level in the working reinforcement $\sigma_{s p}$ have the most significant influence on the opening width of cracks inclined to the longitudinal axis of the beam. So, increasing the relative shear span from 1.06 to 3.08, the opening width of inclined cracks increases with respect to the average value $\left(b_{0}\right)$ by $26.4 \%$. By increasing the width ratio of the table overhangs to the rib thickness from 2 to 4 and prestressing from 0 to $30 \mathrm{kN} / \mathrm{cm}^{2}$, the opening width of inclined cracks will decrease by 20.7 and $11 \%$, respectively.

There is also the mutual interaction of the factors. With a simultaneous increase of $a / h_{0}$ and $b_{f}^{\prime} / b, a / h_{0}$ and $h_{f}^{/} / h_{0}, a / h_{0}$ and $\sigma_{s p}$, the value $w_{c r c, /}$ will decrease. With a simultaneous increase of $b_{f}^{/} / b$ and $h_{f}^{/} / h_{0}, b_{f}^{/} / b$ and $\rho_{s w}, h_{f}^{/} / h_{0}$ and $\sigma_{s p}, h_{f}^{/} / h_{0}$ and $\rho_{s w}, \rho_{s w}$ and $\sigma_{s p}$, the value $w_{c r c, /}$ will increase.

It is very important that the average opening width of inclined cracks is almost twice the allowable value. Since the amount of cross reinforcement, studied in the experiments and used in practice, had an insignificant effect (up to $5 \%$ ) on the opening width of inclined cracks, it can be assumed that for these purposes, it is necessary to increase the rib width and the amount of cross reinforcement. 
It is particularly remarkable that the width of the overhangs and the thickness of the table play a significant role in the opening width of normal cracks as well as inclined ones, which must be taken into account in the calculations.

Also, according to the test results, an adequate experimental-statistical dependence (mathematical) model of the projection value of a dangerous inclined crack was obtained:

$$
\hat{Y}\left(c_{0}\right)=28.0+14.2 X_{1}-2.6 X_{5}-1.4 X_{1} X_{5} \quad(\mathrm{~cm})
$$

The analysis of this model shows that the relative shear span and the prestressing level in the working reinforcement have a significant impact on the size of a dangerous inclined crack. The rest of the factors were insignificant.

So, by increasing the relative span of the section from 1.0 to 3.18 , the projection value of a dangerous inclined crack will increase in relation to the average value $\left(b_{0}\right)$ by $101.4 \%$. By increasing the prestressing level from 0 to $30 \mathrm{kN} / \mathrm{cm}^{2}$, it decreased by $18.6 \%$.

A fairly large number of prototypes allowed to conclude that the size of a dangerous inclined crack ranges from $(0.8 \ldots 2.8) h_{0}$, which is a little over the recommended limits 25 . Moreover, this increase is quite reasonable.

After replacing the coded values of the experimental factors with natural ones, the authors obtained an empirical expression for determining the projection of a dangerous inclined crack for prestressed reinforced concrete T-shaped beams:

$$
\hat{c}_{0}=\left[0.8690\left(a / h_{0}\right)+0.0014 \sigma_{s p}-0.0057\left(a / h_{0}\right) \sigma_{s p}-0.040\right] \times h_{0}
$$

where $\sigma_{s p}$ is in $\mathrm{MPa}, c_{0}$ is in $\mathrm{cm}$.

The obtained equation, as well as the experimental data on the projection of a dangerous inclined crack, represent the practical significance of obtained results. It is known that the shear force arising in an inclined section of a reinforced concrete structure consists of three parts, experienced by the concrete in the compressed zone, stretched cross rods crossed by a dangerous inclined crack, and longitudinal reinforcement in the form of a dowel action. Knowing the height and the characteristics of the concrete in the compressed zone, it is easy to determine the sum of the shear forces experienced by the concrete. The value of the dowel action of the longitudinal reinforcement, as a rule, is not more than $10 \%$ and, consequently, it is $5 \%$ of the breaking shear force. Taking into account the value of tensile stresses in the rods of the cross reinforcement at the level of $80 \%$ of its yield point, it is easy to find the value of the shear force experienced by the cross reinforcement (stirrup) if the projection length of a dangerous inclined crack is known, i. e., the intensity of the cross reinforcement. Knowing the values of the design cross force and the projection length of a dangerous inclined crack, it is easy to determine the required value of the cross reinforcement.

Also, there is a rather significant result. During the research, it was found that the experimental values of the cracking load exceed the calculated values by an average of $13 \%$. This must be taken into account in the design stage of reinforced concrete beam elements in order to predict the moment of cracking more accurately.

Based on the obtained data, physical models of bearing capacity of the beam structures will be made. At the same time, it is very important to take into account all their components correctly, which are, as a rule, stochastic (random) values, and to identify objective conformities. On the basis of the installed physical models, refined design schemes and design models of the shear capacity of such a complex composite material as reinforced concrete will be developed.

\section{Conclusions}

In accordance with the obtained test results, the following was found:

(1.) Support areas of experimental reinforced concrete elements with small shear spans $\left(a / h_{0} \approx 1\right)$ are destroyed along an inclined compressed band. The destruction of the support areas of the beam-samples with medium $\left(a / h_{0} \approx 2\right)$ and large $\left(a / h_{0} \approx 3\right)$ shear spans occurs along a dangerous inclined crack from the predominant action of the shear force or bending moment, depending on the stress values in the working reinforcement at the beginning of the crack. The projection length of a dangerous inclined crack significantly exceeds the standard values and depends on the size of the shear span as well as prestressing of the working reinforcement.

(2.) A comparative analysis of Eq. 2 and Eq. 3. Eq. 1 and Eq. 4 showed that the qualitative influence of the investigated factors on the cross load and the moments corresponding to the appearance of the first normal and inclined cracks is generally the same. The main difference is that the loading level at which inclined cracks appear is $53 \%$ higher than the loading level at which the first normal cracks appear in 
the investigated reinforced concrete elements. In this case, as expected, the prestressing level of the main longitudinal reinforcement has a great influence on the loading, which corresponds to the appearance of the first normal cracks in comparison with the loading when the first incline cracks appear, which corresponds to the test data [26 29]. The appearance of inclined cracks was fast, i. e., there was a non-proportional increase of deflections of the investigated elements.

(3.) For a specified ratio of the factors, the opening width of inclined cracks is more than twice the width of normal cracks, and at the operational level, the load reaches its limiting values. The presence of a beam table in the compressed zone of the samples significantly affects not only the crack resistance and deformability but also the strength.

\section{LIST OF SYMBOLS}

$F_{c r c, \perp}^{a c c .}$ Transverse force that causes appearance of inclined cracks $[\mathrm{kN}]$

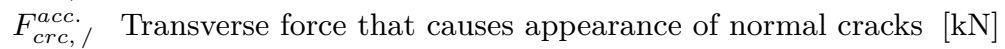

$F_{u} \quad$ Fracture transverse force $[\mathrm{kN}]$

$M_{c r c, \perp}$ Bending moment that causes appearance of normal cracks $[\mathrm{kNm}]$

$M_{c r c, /}$ Bending moment that causes appearance of inclined cracks $[\mathrm{kNm}]$

$w_{c r c, \perp}^{\mathrm{o} 95 F_{u}} \quad$ Normal cracks width $[\mathrm{mm}]$

$w_{c r c, /}^{\mathrm{o}, 95 F_{u}}$ Inclined cracks width [mm]

$c_{\mathrm{o}}$ Projection value of a dangerous inclined crack $[\mathrm{cm}]$

\section{REFERENCES}

[1] O. Harkava, B. Barilyak. Bearing capacity calculation of reinforced concrete crane beams under biaxial bending (in Ukrainian). Collected scientific works of Ukrainian State University of Railway Transport (175):77-83, 2018. https://doi.org/10.18664/1994-7852.175.2018.127166

[2] T. Azizov, O. Melnyk. Experimental studies of rigidity and strength of reinforced concrete elements of box section with normal torsional cracks. Resource-Economical Materials, Constructures, Buildings and Structures (21):82-86, 2011. https://dspace.udpu.edu.ua/handle/6789/665

[3] A. Deifalla, A. Awad, H. Seleem, A. Abdelrahman. Experimental and numerical investigation of the behavior of LWFC L-girders under combined torsion. Structures 26:362-377, 2020. https://doi.org/10.1016/j.istruc.2020.03.070

[4] A. B. Golyshev, V. Kolchunov. Resistance of Reinforced Concrete. Basis, Kyiv, 2009.

[5] A. Iakovenko, I. Kolchunov. The development of fracture mechanics hypotheses applicable to the calculation of reinforced concrete structures for the second group of limit states. Istrazivanja i projektovanja za privredu 15(3):367-376, 2017. https://doi.org/10.5937/jaes15-14662

[6] A. Marí, J. Bairán, A. Cladera, et al. Shear-flexural strength mechanical model for the design and assessment of reinforced concrete beams. Structure and Infrastructure Engineering 11(11):1399-1419, 2014. https://doi.org/10.1080/15732479.2014.964735.

[7] D. De Domenico. Torsional strength of RC members using a plasticity-based variable-angle space truss model accounting for non-uniform longitudinal reinforcement. Engineering Structures 228:111540, 2021. https://doi.org/10.1016/j.engstruct.2020.111540

[8] D. De Domenico, G. Ricciardi. Shear strength of RC beams with stirrups using an improved Eurocode 2 truss model with two variable-inclination compression struts. Engineering Structures 198:109359, 2019. https://doi.org/10.1016/j.engstruct.2019.109359

[9] V. M. Karpiuk. Calculating Models of Power Resistance of the Span Reinforced Concrete Constructions at the General Case of Stress State. ODABA, Odesa, 2014.

[10] Recommendations on the use of reinforcing steel according to DSTU 3760-98 in the design and manufacture of structures without prestressing reinforcement, Gosstroy of Ukraine, Technical Committee for Standardization "Reinforcement for Reinforced Concrete Structures", Kiev, 2002.

[11] DSTU 3760-98. Reinforcing steel for reinforced concrete structures, Gosstandart of Ukraine, Kiev, 1998.

[12] V. S. Dorofeev, V. M. Karpiuk, F. R. Karpiuk. Calculation of deflections of prestressed reinforced concrete T-elements. Mechanics and Physics of Building Materials and Structures Destruction (8):402-415, 2009.

[13] V. S. Dorofeev, V. M. Karpiuk, F. R. Karpiuk. Strength calculation of support sections of prestressed reinforced concrete T-elements. Diagnosis, Durability and Reconstruction of Bridges and Building Structures (11):13-26, 2009.

[14] V. S. Dorofeev, V. M. Karpiuk, F. R. Karpiuk. Modeling of stress-strain state of prestressed concrete T-beams used in agro-industrial construction. In Proceedings of the International Scientific and Practical Forum "Ecological, Technological and Socio-Economic Aspects of Effective Use of Material and Agricultural Base of AIC", 1, pp. 522-530. 2008. 
[15] V. M. Karpiuk, Y. A. Syomina, D. V. Antonova. Calculation models of the bearing capacity of span reinforced concrete structure support zones. Materials Science Forum 968:209-226, 2019. https://doi.org/10.4028/www.scientific.net/MSF.968.209

[16] V. A. Voznesenskiy. Statistical Methods of Designing an Experiment in Feasibility Studies. Finance and Statistics, Moscow, 1981.

[17] V. A. Voznesenskiy, T. V. Lyashenko, B. L. Ogarkov. Numerical methods for solving construction and technological problems with a computer. High school, Kyiv, 1989.

[18] P. I. Vasiliev, O. A. Rochnyak, N. N. Yaroshin. Influence of the nature of cracking on the resistance of reinforced concrete elements to shear force. Improving the Methods of Calculation and Research of Types of Reinforced Concrete Structures (1):19-25, 1981.

[19] A. S. Zalesov, O. F. Ilyin. Crack resistance of reinforced concrete elements inclined sections. Limit State of Reinforced Concrete Structures Elements (1):56-68, 1976.

[20] Y. Y. Luchko, V. N. Chubrikov, V. F. Lazar. Strength, Crack Resistance and Durability of Concrete and Reinforced Concrete Structures on the Basis of Fracture Mechanics. Kamenar, Lviv, 1999.

[21] Y. L. Izotov. Strength of Reinforced Concrete Beams. Budivelnik, Kiev, 1978.

[22] O. V. Romashko, V. M. Romashko. Model of multilevel formation of normal cracks in reinforced concrete elements and structures. IOP Conference Series: Materials Science and Engineering 708:012069, 2019. https://doi.org/10.1088/1757-899X/708/1/012069.

[23] V. Romashko, O. Romashko. Calculation of the crack resistance of reinforced concrete elements with allowance for the levels of normal crack formation. MATEC Web of Conferences 230:02028, 2018. https://doi.org/10.1051/matecconf/201823002028.

[24] V. I. Kolchunov, A. I. Demianov, I. A. Iakovenko, M. O. Garba. Bringing the experimental data of reinforced concrete structures crack resistance in correspondence with their theoretical values (in Russian). Science and Construction 15(1):42-49, 2018. https://doi.org/10.33644/scienceandconstruction.v0i1(15).7.

[25] National building standards of Ukraine "Concrete and Reinforced Concrete Structures", Minregionbud, Kyiv, 2011.

[26] F. S. Zamaliev. Numerical and full-scale experiments of prestressed hybrid reinforced concrete-steel beams (in Russian). Vestnik MGSU (3):309-321, 2018. https://doi.org/10.22227/1997-0935.2018.3.309-321

[27] I. Iakovenko, V. Kolchunov, I. Lymar. Rigidity of reinforced concrete structures in the presence of different cracks. MATEC Web of Conferences 116:02016, 2017. https://doi.org/10.1051/matecconf/201711602016

[28] Z. Blikharskyy, R. Vashkevych, P. Vegera, Y. Blikharskyy. Crack resistance of RC beams on the shear. In Proceedings of CEE 2019, pp. 17-24. Springer International Publishing, 2019. https://doi.org/10.1007/978-3-030-27011-7_3

[29] P. Vegera, R. Khmil, R. Vashkevych, Z. Blickharskyy. Comparison crack resistance of RC beams with and without transverse reinforcement after shear testing. Quality Production Improvement - QPI 1(1):342-349, 2019. https://doi.org/10.2478/cqpi-2019-0046. 